\title{
Platelet dysfunction in platelet-type von Willebrand disease due to the constitutive triggering of the Lyn-PECAM1 inhibitory pathway
}

Loredana Bury, Emanuela Falcinelli, Anna Maria Mezzasoma, Giuseppe Guglielmini, Stefania Momi and Paolo Gresele

Department of Medicine and Surgery, Section of Internal and Cardiovascular Medicine, University of Perugia, Perugia, Italy

\author{
Correspondence: \\ Loredana Bury \\ loredana.bury@gmail.com \\ Received: $\quad$ March 18, 2021. \\ Accepted: July 29, 2021. \\ Prepublished: $\quad$ August 19, 2021. \\ https://doi.org/10.3324/haematol.2021.278776 \\ ๑2022 Ferrata Storti Foundation \\ Haematologica material is published under a CC \\ BY-NC license @(1) $\Theta$
}

\begin{abstract}
Platelet-type von Willebrand disease (PT-VWD) is an inherited platelet disorder. It is characterized by macrothrombocytopenia and mucocutaneous bleeding, of variable severity, due to gain-of-function variants of GP1BA conferring to glycoprotein Ib $\alpha$ (GPIba) enhanced affinity for von Willebrand factor (VWF). The bleeding tendency is conventionally attributed to thrombocytopenia and large VWF-multimer depletion. However, while some indications suggest that platelet dysfunction may contribute to the bleeding phenotype, no information on its characteristics and causes are available. The aim of the present study was to characterize platelet dysfunction in PT-VWD and shed light on its mechanism. Platelets from a PT-VWD patient carrying the p.M239V variant, and from PT-VWD mice carrying the p.G233V variant, showed a remarkable platelet function defect, with impaired aggregation, defective granule secretion and reduced adhesion under static and flow conditions. VWFbinding to GPIba is known to trigger intracellular signaling involving Src-family kinases (SFK). We found that constitutive phosphorylation of the platelet SFK Lyn induces a negative-feedback loop downregulating platelet activation through phosphorylation of PECAM1 on Tyr686 and that this is triggered by the constitutive binding of VWF to GPIba. These data show, for the first time, that the abnormal triggering of inhibitory signals mediated by Lyn and PECAM1 may lead to platelet dysfunction. In conclusion, our study unravels the mechanism of platelet dysfunction in PT-VWD caused by deranged inhibitory signaling. This is triggered by the constitutive binding of VWF to GPIba which may significantly contribute to the bleeding phenotype of these patients.
\end{abstract}

\section{Introduction}

Gain-of-function variants in the GP1BA gene conferring to GPIba enhanced affinity for VWF cause platelet-type von Willebrand disease (PT-VWD), a rare inherited bleeding disorder. ${ }^{1,2}$ Patients with PT-VWD have mild thrombocytopenia with increased platelet volume, enhanced ristocetin-induced platelet agglutination (RIPA) and prolonged bleeding time associated with mucocutaneous bleeding, which can be severe. ${ }^{3}$ The cause of the apparently counterintuitive bleeding phenotype of patients with platelets displaying enhanced affinity for VWF is incompletely understood and is thought to be due, principally, to thrombocytopenia and to the consumption of large VWF-multimers bound to platelets. ${ }^{1}$

The possibility that platelet dysfunction may contribute to the bleeding phenotype of PT-VWD has attracted little attention, but defective fibrinogen binding, delayed aggregation in response to ADP and thrombin, impaired thrombus formation on a damaged carotid artery and unstable clot formation have been reported in a mouse model of PT-VWD, ${ }^{4,5}$ raising the hypothesis that platelet function may be altered in PT-VWD patients. However, the mechanism of the platelet function defect is unknown and no functional studies have been performed with human PT-VWD platelets.

The first step in primary hemostasis is the interaction between platelets and subendothelial collagen, mediated by the binding of von Willebrand factor (VWF) to the exposed collagen and to the GPIba subunit of the platelet GPIb-IX-V complex. This slows down platelets onto the damaged vessel wall thus allowing the direct interaction 
of collagen with its receptors on platelets. However, GPIb$I X-V$ engagement by VWF also triggers intraplatelet signaling with the sequential activation of the Src-family kinases (SFK) Src and Lyn. These are associated with the cytoplasmic tail of GPIba, which triggers a cytoplasmic $\mathrm{Ca}^{2+}$ increase and PI3-kinase/PKC activation, ultimately leading to inside-out $\alpha_{111} \beta_{3}$ activation. ${ }^{6-8}$

Here, for the first time, we show defective platelet function in a PT-VWD patient carrying the P.M239V variant and in PT-VWD mice carrying the p.G233V variant, due to impaired Rap1b and $\alpha_{11 \mathrm{~b}} \beta_{3}$ activation. Mechanistic studies revealed a constitutive phosphorylation of Lyn inducing a negative-feedback loop, downregulating platelet activation through the phosphorylation of PECAM1 on Tyr686.

Our results, showing that constitutive binding of VWF to GPIb $\alpha$ triggers PECAM1-mediated inhibitory signaling downregulating platelet activation, suggest that defective platelet function in PT-VWD may significantly contribute to the bleeding phenotype associated with this disorder.

\section{Methods}

The control and PT-VWD terms in this manuscript refer to human platelets while the respective terms used for murine platelets are $\operatorname{Tg}^{\mathrm{WT}}$ and $\operatorname{Tg}^{\mathrm{G} 233 \mathrm{~V}}$. All human and animal studies were approved by the competent institutional review boards (human: CEAS Umbria, approval n. 2663/15; animal: Italian Ministry of Public Health, authorization $n$. 561/2015-PR).

\section{Human studies and blood sampling}

The PT-VWD patient carrying the M239V GP1BA variant (to our knowledge the only patient so far diagnosed in Italy) has been previously reported; 910 she had an ISTH-BAT score of $11 .{ }^{11}$ Each experiment was repeated three to five times from blood samples collected on different days (in the text indicated as independent experiments, eight in total, Online Supplementary Table S1). Age-and sexmatched healthy controls were studied in parallel. For details see the Online Supplementary Data.

\section{Mouse strains and blood sampling}

The generation of PT-VWD mice expressing human GP1BA carrying the p.G233V variant ( $\mathrm{gg}^{\mathrm{G} 233 \mathrm{~V}}$ ), and of control mice expressing a wild-type human GP1BA $\left(\operatorname{Tg}^{\mathrm{WT}}\right)$, has been previously described (Online Supplementary Figure S1).4,5,10,12 Mice were bred and housed in the animal facility at the University of Perugia, Italy, and all experiments were performed using 3- to 6- month-old mice. The number of males and females, as well as platelet counts, are reported under each figure legend. For details see the Online Supplementary Data.

\section{Light transmission aggregometry (LTA)}

LTA was carried out using platelet-rich plasma (PRP) employing a range of agonists, as described previously. ${ }^{13}$ For the study of shape change, PRP was pretreated with the Arg-Gly-Asp-Ser peptide (RGDS) $\alpha_{111} \beta_{3}$ blocker. ${ }^{14,15}$ For details see the Online Supplementary Data.

\section{$\alpha_{116} \beta_{3}$ activation}

$\alpha_{110} \beta_{3}$ activation was assessed using the PAC-1 MoAb (BD Bioscience, Franklin Lakes, NJ, USA) for human platelets and the JON/A MoAb (Emfret Analytics, Eibelstadt, Germany) for murine platelets, as described previously. ${ }^{13,17}$ For details see the Online Supplementary Data.

\section{Granule content and secretion}

Platelet granule content was assessed by electron microscopy, as described previously. ${ }^{10,13}$

Alpha-granule secretion was measured as P-selectin expression ${ }^{18-20}$ and dense granule content and release using the green fluorescent dye mepacrine ${ }^{21}$ by flow cytometry, as described previously. ${ }^{19}$ For details see the Online Supplementary Data.

\section{Spreading assay}

We resuspended washed platelets ${ }^{22,23}\left(20 \times 10^{6} / \mathrm{mL}\right)$ in Tyrode's buffer and spreading on fibrinogen and type I collagen was assessed, as described previously. ${ }^{24}$ For details see the Online Supplementary Data.

\section{Platelet adhesion under flow conditions}

Platelet adhesion under flow conditions over fibrillar type I collagen was assessed using citrated human or murine blood, as described previously. ${ }^{20,25}$ For details see the Online Supplementary Data.

\section{Measurement of intracellular calcium $\left(\mathrm{Ca}^{2+}\right)$}

PRP was loaded with the $\mathrm{Ca}^{2+}$-sensitive dye FLUO 3-acetoxymethyl ester (FLUO 3-AM; Molecular Probes) and $\mathrm{Ca}^{2+}$ mobilization induced by various agonists was assessed by flow cytometry. as described previously. ${ }^{17,26}$ For details see the Online Supplementary Data.

\section{Rap-1b pull-down assay}

Rap-1b activity (Rap-1b-GTP) was assessed using an active Rap-1b pull-down and detection kit (Pierce Biotechnology, Rockford, IL, USA) in washed platelets stimulated for 30 seconds with ADP $10 \mathrm{mM}$, thrombin $0.1 \mathrm{U} / \mathrm{mL}$ or their vehicle. ${ }^{27}$ For details see the Online Supplementary Data.

\section{Phosphorylation of signaling proteins}

Human washed platelets $\left(300 \times 10^{\%} / L\right)$ were stimulated for 30 seconds under continuous stirring with ADP $2 \mu \mathrm{M}, \mathrm{CVX}$ $60 \mathrm{ng} / \mathrm{mL}$, ristocetin $0.3 \mathrm{mg} / \mathrm{mL}$ or their vehicle. To exclude 
$\alpha_{11 \mathrm{~L}} \beta_{3}$-mediated outside-in signaling as a cause of signaling protein phosphorylation, platelets were treated with the $\alpha_{11 b} \beta_{3}$ inhibitor tirofiban $0.4 \mu \mathrm{M}$ for ten minutes before stimulation. Phosphorylation of Src (Tyr 416), Lyn (Tyr397 and Tyr507), PLC $\beta_{3}$ (Ser537), Akt (Ser473), Syk (Tyr525/526) PKC substrate, PECAM1 (Tyr686 and Ser702), ${ }^{28}$ was analyzed by western blotting, as described previously. ${ }^{10}$ For details see the Online Supplementary Data.

\section{CAMP and CGMP production}

cAMP production in response to lloprost $(100 \mathrm{ng} / \mathrm{mL})$ and cGMP production in response to the nitric oxide (NO)donor s-nitroso-n-acetyl penicillamine (SNAP, 0.1-1-10 $\mu \mathrm{M}$ ) was assessed using the dual range cAMP Enzymeimmunoassay Biotrak (EIA) System and the dual range cGMP Enzymeimmunoassay Biotrak (EIA) System (Amersham, GE Healthcare, Milan, Italy).

\section{Results}

\section{Platelet aggregation and shape change are defective in PT-VWD}

The aggregation of human PT-VWD platelets was strongly impaired in response to TRAP-6, defective in response to collagen, convulxin and arachidonic acid and lacking the second wave in response to ADP and epinephrine (Figure 1A, Online Supplementary Figure S2). Given that the analysis of LTA curves suggested a shape change defect, LTA was repeated after pre-incubation with RGDS, which prevents aggregation. This allowed a more thorough observation of the initial phase of the platelet activation response to stimuli; indeed shape change turned out to be significantly reduced in response to all agonists (Figure 1B).

Platelet $\alpha_{11 \mathrm{~b}} \beta_{3}$ activation and granule secretion are defective in PT-VWD

PAC-1 binding to human PT-VWD platelets (Figure 2A, Online Supplementary Figure S3A) and JON/A binding to $\mathrm{Tg}^{\mathrm{G} 233 \mathrm{~V}}$ mouse platelets (Figure 2B) were impaired in response to all tested stimuli. PAC-1 and JON/A binding in resting conditions did not differ between control and PT-VWD platelets and between $\operatorname{Tg}^{\mathrm{WT}}$ and $\mathrm{Tg}^{\mathrm{G} 233 \mathrm{~V}}$ platelets, suggesting that the mildly increased volume of PT-VWD and $\operatorname{Tg}^{\mathrm{G} 233 \mathrm{~V}}$ platelets did not influence flow cytometry results.

The defect of second wave aggregation suggested a granule secretion defect. Granule content, evaluated by transmission electron microscopy, was normal in human PT-VWD platelets compared to controls ( $\alpha$-granules: $5.8 \pm 0.4$ vs. $6.4 \pm 1.3 /$ platelet; dense granules: $0.7 \pm 0.4$ vs. $0.9 \pm 0.3$ /platelet, $P=n s$ ) (Figure $2 C$ ), while secretion of both

A
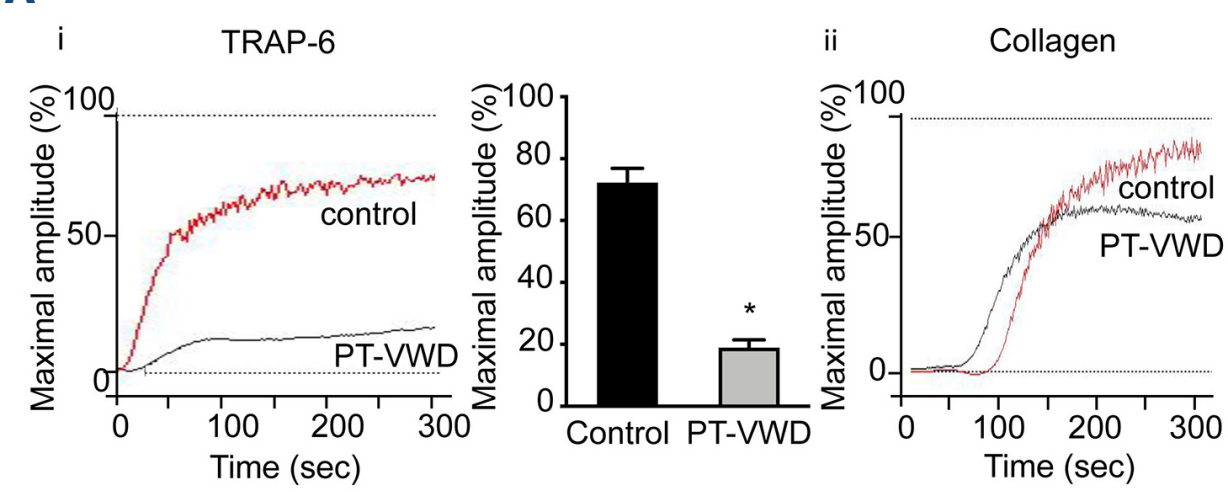

PLATELET AGGREGATION
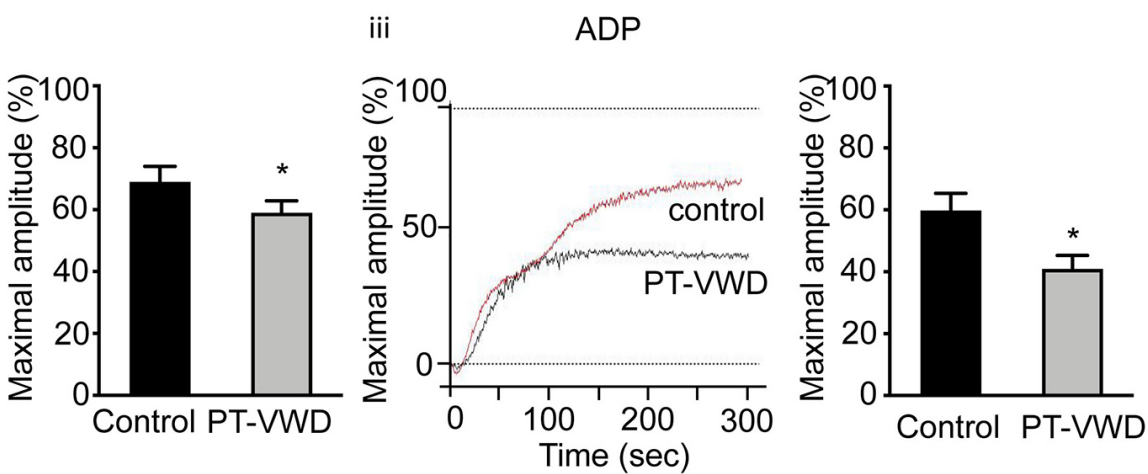

B
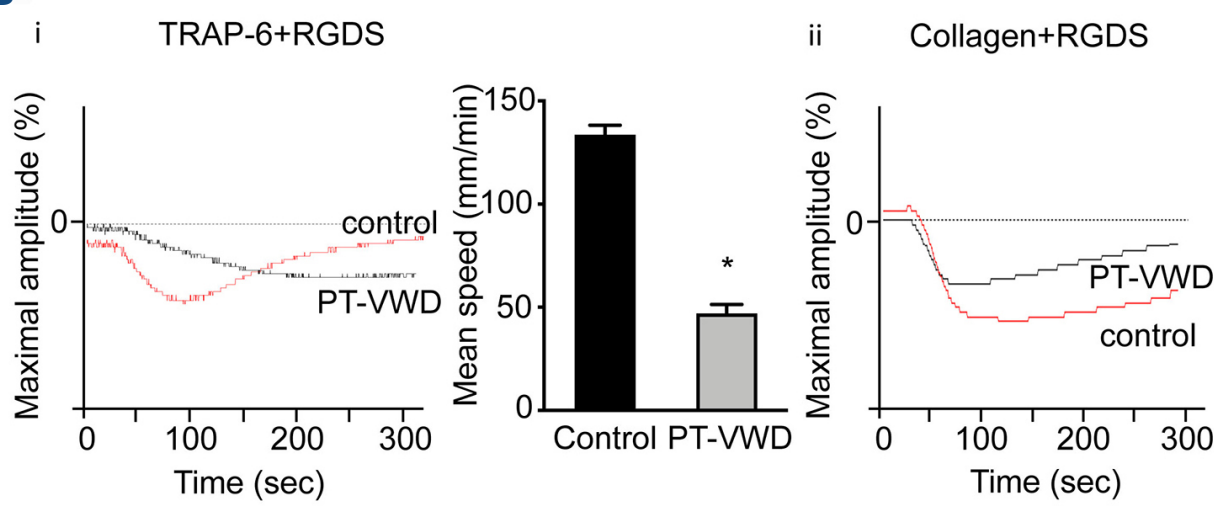

PLATELET SHAPE CHANGE
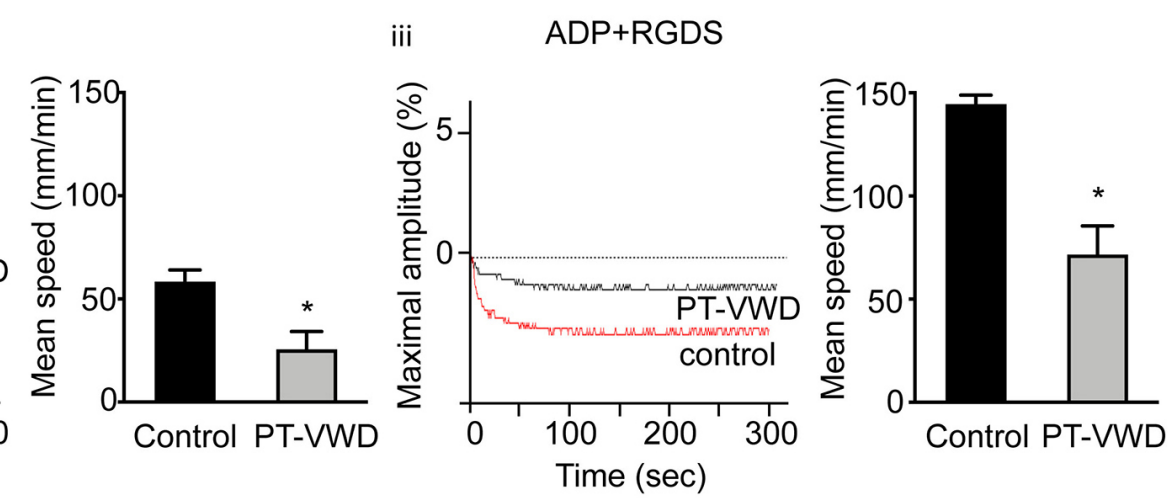

Figure 1. Platelet aggregation and shape change are defective in PT-VWD. (A) Human platelet aggregation in response to TRAP$620 \mu \mathrm{M}$ (i), ADP $10 \mu \mathrm{M}$ (ii) and collagen $1 \mathrm{mg} / \mathrm{mL}$ (iii) in platelet-rich plasma from the PT-VWD patient and a parallel healthy control. Traces are representative of four independent experiments (Online Supplementary Table S1, samples A, C, D, E). * $=P<0.05$ vs. control, unpaired Student's $t$ test. (B) Platelet shape change assessed by LTA after pretreatment with RGDS (120 $\mu g / m L)$ in response to TRAP-6 $2 \mu \mathrm{M}$ (i), ADP $10 \mu \mathrm{M}$ (ii) and collagen $1 \mathrm{mg} / \mathrm{mL}$ (iii) in platelet-rich plasma from the PT-VWD patient and a parallel healthy control. Tracings are representative of four independent experiments (Online Supplementary Table S1, samples A, C, D, E) ${ }^{\star} P<0.05$ vs. control, unpaired Student's $t$ test. 
A

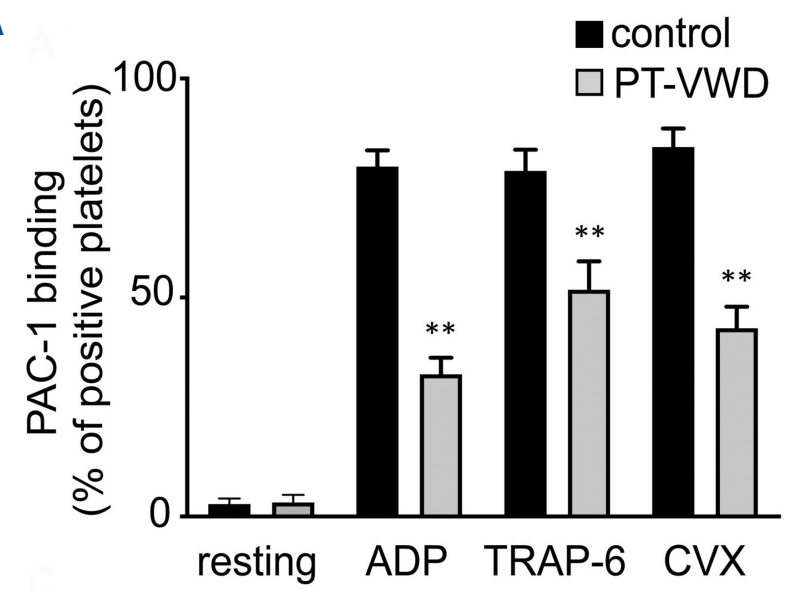

B

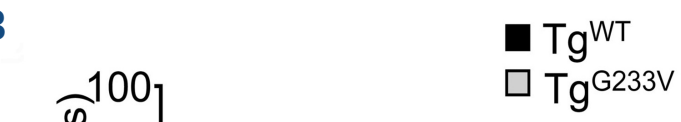

C

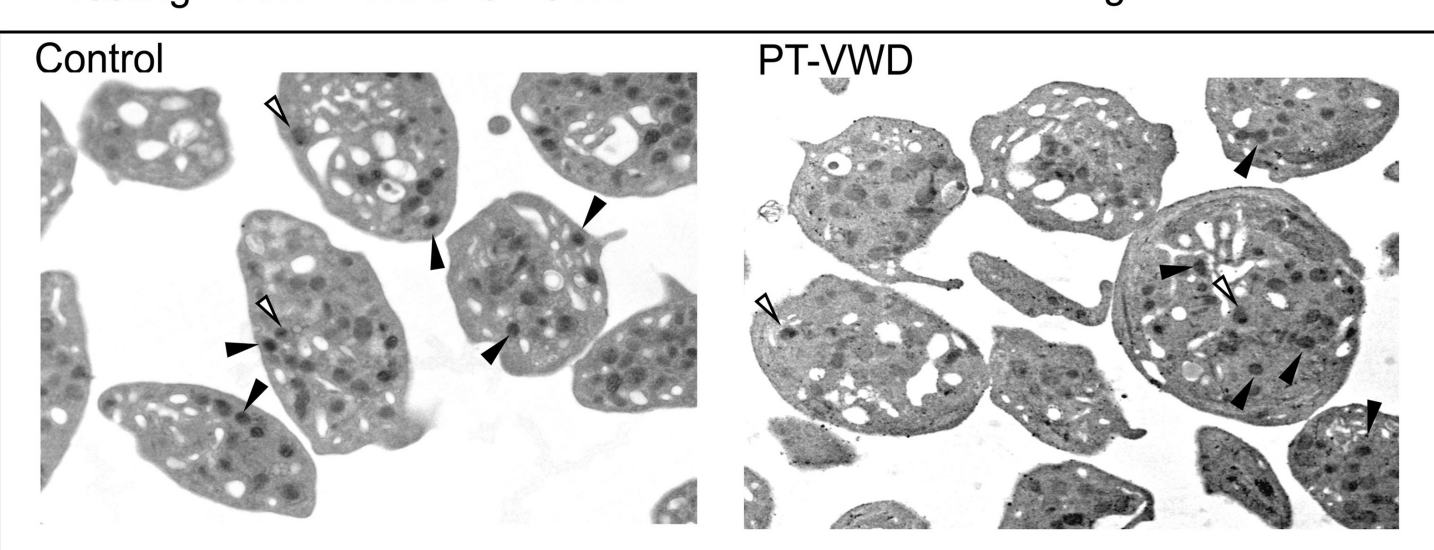

D

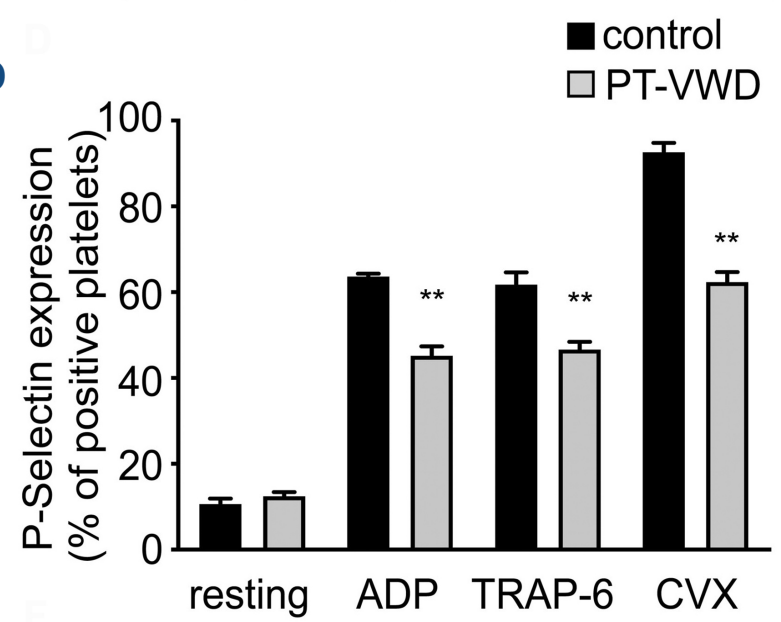

F

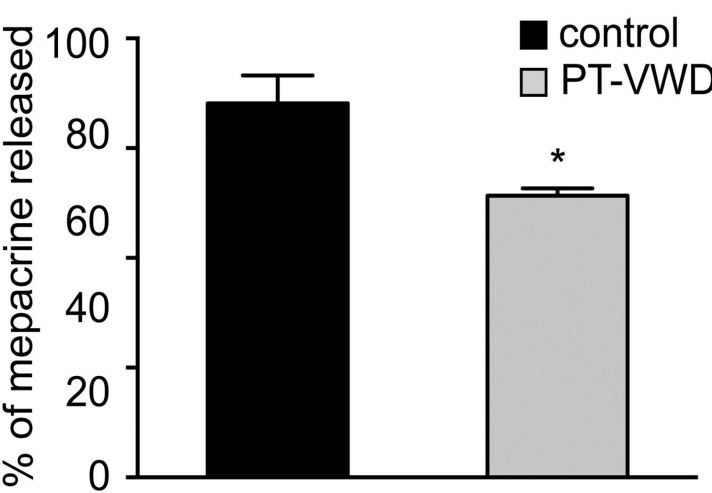

E

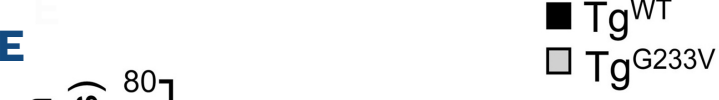

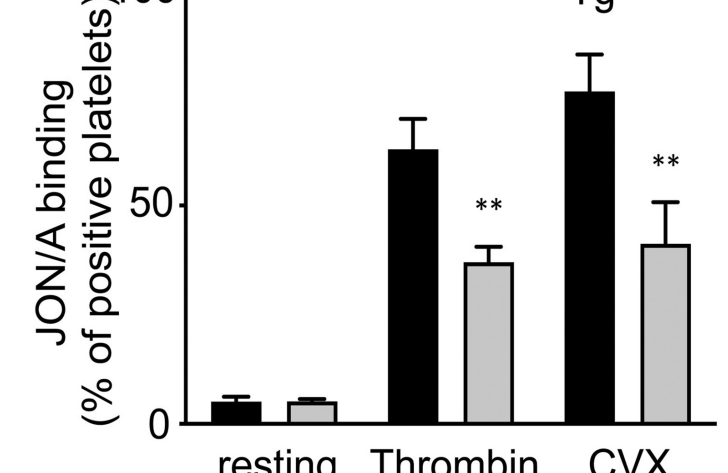

resting Thrombin CVX 
membrane. D-E) $\alpha$-granule secretion in human (D) and murine (E) platelets as assessed by the measurement of P-selectin expression by flow cytometry. Agonists were ADP $10 \mu \mathrm{M}$, TRAP6 $10 \mu \mathrm{M}$ or CVX $20 \mathrm{ng} / \mathrm{mL}$ for human platelets and thrombin 0.05 $\mathrm{U} / \mathrm{mL}+$ GPRP $2 \mu \mathrm{M}$ or CVX $25 \mathrm{ng} / \mathrm{mL}$ for murine platelets. P-selectin expression is reported as a percentage of positive platelets, calculated as the percentage of platelets (gated for their forward scatter and side scatter values and for their positivity to the platelet marker CD41) that bound CD62P over the total platelet population, after setting for aspecific binding. Data are means \pm SEM from at least five independent experiments (Online Supplementary Table S1, samples A, B, C, D, E) or from n=5 mice (TgWT: three females and two males, mean platelet count: $627850 \pm 21566 / \mathrm{mL}$; g $^{\mathrm{G} 233 \mathrm{~V}}$ : three females and two males; mean platelet count: $330600 \pm 17677 / \mu \mathrm{L}) . * \star P<0.01$; two-way ANOVA. $(F, G)$ Dense granule secretion in human $(F)$ and murine $(G)$ platelets as assessed by the measurement of mepacrine release by flow cytometry. Mepacrine release was calculated by the following formula: 1-(residual mepacrine content after thrombin stimulation with $0.05 \mathrm{U} / \mathrm{mL} /$ total mepacrine incorporated)x100. "Total mepacrine incorporated" is the percentage of platelets (gated for their forward scatter and side scatter values and for their positivity to the platelet markers CD41 or CD42b) that incorporated mepacrine over the total platelet population, after setting for aspecific binding; "residual mepacrine content" is the percentage of platelets stimulated with $0.05 \mathrm{U} / \mathrm{mL}$ of thrombin that incorporated mepacrine over the total platelet population, after setting for aspecific binding. Data are means \pm SEM from at least 5 independent experiments (Online Supplementary Table S1, samples A, B, C, D, E) or from n=5 mice ( Tg $^{\mathrm{WT}}$ : three females and two males, mean platelet count: $627850 \pm 21566 / \mu \mathrm{L} ; \mathrm{Tg}^{\mathrm{G} 233 \mathrm{~V}}$ : three females and two males; mean platelet count: $330600 \pm 17677 / \mathrm{mL}$ ). $\star P<0.05, \star * P<0.01$; unpaired Student's $t$ test.

$\alpha$ - and dense granules was defective with both human PTVWD and murine TgG233V platelets, as shown by impaired agonist-induced platelet surface P-selectin expression (Figure 2D and 2E, Online Supplementary Figure $S 3 B$ ) and mepacrine release (Figure 2F, G). P-selectin expression (Figure $2 \mathrm{C}$ ) and mepacrine incorporation did not differ between control and PT-VWD resting platelets (mepacrine incorporation: $85.9 \pm 9 \%$ vs. $94.7 \pm 4 \%, P=n s$ ) and between $\mathrm{Tg}^{\mathrm{WT}}$ and $\mathrm{Tg}^{\mathrm{G} 233 \mathrm{~V}}$ platelets (mepacrine incorporation: $76.5 \pm 14.2 \%$ vs. $84.3 \pm 11.3 \%, P=n s$ ), here too suggesting that the mildly increased volume of PT-VWD and $\operatorname{Tg}^{\mathrm{G} 233 \mathrm{~V}}$ platelets did not affect flow cytometry results. Platelet surface expression of $\alpha_{111} \beta_{3}$ and GPIb/IX/V receptors was comparable between PT-VWD and control platelets (data not shown).

\section{Spreading and adhesion under flow conditions are defective in PT-VWD}

Platelet spreading on fibrinogen and type I collagen was defective both with human PT-VWD (Figure 3A, B) and murine $\mathrm{Tg}^{\mathrm{G} 233 \mathrm{~V}}$ platelets (Figure $3 \mathrm{C}$ ), compared with controls. Also, total surface area covered by platelets upon perfusion of blood over a collagen-coated surface was significantly reduced as compared with controls, both at high $\left(\alpha_{11 b} \beta_{3}\right.$-dependent) and low $\left(\alpha_{11 \mathrm{~b}} \beta_{3}\right.$-independent) shear rates (Figure 3D, E). ${ }^{29}$

Given that granule secretion, shape change, platelet spreading on type I collagen and adhesion at low shear rate do not depend on $\alpha_{11 b} \beta_{3}$ activation, a global platelet function defect in PT-VWD was suspected, therefore signal transduction mechanisms were explored.

\section{Platelet $\mathrm{Ca}^{2+}$ mobilization and Rap-1b activation are impaired in PT-VWD}

We first studied cytoplasmic free calcium movements which are involved in shape change, adhesion, aggregation and the release of platelet granules, ${ }^{30}$ all processes defective in PT-VWD. Indeed, ADP-, TRAP-6- and CVX-induced calcium mobilization was impaired in human
PT-VWD platelets (Figure 4A). The activation of the small GTPase Rap1b, which is $\mathrm{Ca}^{2+}$-mediated ${ }^{31}$ and is required for $\alpha_{11 \mathrm{~b}} \beta_{3}$ activation, was also impaired in response to ADP and thrombin in human PT-VWD (Figure 4B) and Tg ${ }^{\mathrm{G} 233 \mathrm{~V}}$ (Online Supplementary Figure S4A) platelets. The phosphorylation of PLC $\beta_{3}$, activator of Rap1b, ${ }^{32}$ was comparable between PT-VWD and control platelets upon activation with ADP and thrombin (Online Supplementary Figure S4B).

SFK are crucial steps in the pathways leading to the cytoplasmic $\mathrm{Ca}^{2+}$ increase, and reciprocally, $\mathrm{Ca}^{2+}$ rises modulate SFK activation and activate Rap1b. ${ }^{32,33}$ Another key pathway regulating Rap $1 \mathrm{~b}$ is triggered by $\mathrm{PKC}$ activation ${ }^{34}$ thus we explored SFK and PKC activation.

\section{Src-family kinases, Lyn and PECAM1 are constitutively activated in PT-VWD platelets}

SFK are phosphorylated upon agonist binding to a wide repertoire of platelet surface receptors and thus play a central role in transducing activatory signals; ${ }^{35}$ we therefore assessed their phosphorylation. Phosphorylation of SFK was markedly enhanced in resting PT-VWD and Tg ${ }^{\mathrm{G} 233 \mathrm{~V}}$ platelets compared to controls (Figure 5A, Online Supplementary Figure S5A). Interestingly, control and $\mathrm{Tg}^{\mathrm{WT}}$ platelets pre-incubated with ristocetin, which triggers the binding of VWF to GPIba, showed enhanced SFK phosphorylation (Figure 5A, Online Supplementary Figure S5A). We focused on Lyn because it is the member of SFK which, besides playing a role in platelet activatory signaling, also triggers a signaling that dampens platelet activation by phosphorylating immunotyrosine-based inhibitory motif (ITIM)-containing receptors. ${ }^{35}$ Lyn was phosphorylated at Tyr397, which means activated, in resting PT-VWD and Tg ${ }^{\mathrm{G} 233 \mathrm{~V}}$, but not in control platelets (Figure 5B, Online Supplementary Figure S5B). Interestingly, here too ristocetin triggered the phosphorylation of Lyn at Tyr397 of control and $\operatorname{Tg}^{\mathrm{WT}}$ platelets. Accordingly, the negative regulatory site of Lyn - Tyr507 - was less phosphorylated in PT-VWD and $\operatorname{Tg}^{\mathrm{G} 233 \mathrm{~V}}$ platelets than in control and $\mathrm{Tg}^{\mathrm{WT}}$ platelets, while the incubation with ristocetin triggered 
the de-phosphorylation at Tyr507 of control platelets (Figure 5C, Online Supplementary Figure S5C). Moreover, the ITIM-containing platelet receptor PECAM1, a substrate of Lyn, ${ }^{36}$ was phosphorylated at Tyr686 and Ser702 (Ser702 is phosphorylated after residue 686), thus activated, in resting PT-VWD and $\operatorname{Tg}^{\mathrm{G} 233 \mathrm{~V}}$ but not in control platelets. Here too, ristocetin triggered the PECAM1 phosphorylation of control platelets and $\mathrm{Tg}^{\mathrm{WT}}$ platelets (Figure 5D, 5E, Online Supplementary Figure S5D, E).

Upon platelet stimulation, SFK and Lyn (Tyr397) phosphorylation was only mildly increased in PT-VWD platelets while it was markedly increased in control platelets (Online Supplementary Figure S6A, B). On the contrary, Lyn phosphorylation at Tyr507 was significantly increased in activated PT-VWD platelets compared to control platelets (Online Supplementary Figure S6C). Finally, upon platelet stimulation, PECAM1 phosphorylation of PT-VWD platelets was comparable to control platelets (Online Supplementary Figure $S 6 D, E$ ).

We then focused on the activation of the main Lyn substrates, Akt and Syk: Akt phosphorylation was comparable in resting PT-VWD and control platelets while it was diminished in PT-VWD platelets upon stimulation with ADP and CVX (Online Supplementary Figure S7); Syk phosphorylation was comparable both in resting and in stimulated PT-VWD and control platelets (Online Supplementary Figure S7).

On the other hand, PKC substrate phosphorylation was increased in resting PT-VWD platelets. Here too, ristocetin triggered the phosphorylation of PKC substrates of control platelets (Figure 5F, Online Supplementary Figure S5F). Upon platelet stimulation, PKC substrate phosphorylation was only mildly increased in PT-VWD platelets while it was increased twofold in control platelets, with a significant difference between control and PT-VWD platelets (Online Supplementary Figure S6F).

CAMP and CGMP production were comparable between control and PT-VWD platelets (Online Supplementary Figure S8).

\section{Discussion}

The bleeding diathesis of PT-VWD patients has been conventionally attributed to the clearance of platelet-VWF complexes from the circulation.' Recently, we showed that defective proplatelet formation and ectopic platelet release by megakaryocytes in the bone marrow contribute to thrombocytopenia in PT-VWD..$^{10}$ However, the mild to moderate thrombocytopenia of PT-VWD does not seem sufficient to explain a bleeding phenotype that may sometimes be severe, especially after surgery and delivery. ${ }^{1,37-41}$ Previous studies in $\mathrm{Tg}^{\mathrm{G} 233 \mathrm{~V}}$ mice showed defective fibrinogen binding, ${ }^{4}$ decreased pro-coagulant activity, delayed aggregation in response to ADP and thrombin and impaired in vivo thrombus formation, ${ }^{5}$ suggesting platelet dysfunction in these mice. Similarly, studies on platelets from a patient with type-2B von Willebrand disease (2B-VWD), which is the VWF counterpart of PT-VWD, and from $2 B-V W D$ mice, both carrying the p.V1316M VWF variant, showed that the constitutive binding of mutant VWF to platelets causes impaired platelet function with reduced $\alpha_{111} \beta_{3}$ activation, contributing to the bleeding tendency of 2B-VWD. ${ }^{42,43}$ However, no studies on platelet function in PT-VWD patients have ever been performed.

Here we show that a remarkable platelet function defect is present in PT-VWD patients and we discovered that it is caused by the constitutive triggering of platelet inhibitory signal transduction negatively regulating platelet activation through the hyper-activation of Lyn and PECAM1.

Our study focused on two different well known GP1BA gain-of-function variants: p.M239V, carried by a PT-VWD patient, and p.G233V, expressed in PT-VWD mice. PT-VWD platelets showed defective $\alpha_{11 \mathrm{~b}} \beta_{3}$ activation and, consequently, impaired platelet aggregation, spreading on fibrinogen and adhesion to collagen at high shear rates, all processes dependent on $\alpha_{11 b} \beta_{3}$ activation. Moreover, PTVWD platelets showed defective $\alpha$ - and $\delta$-granule secretion, shape change and adhesion to collagen at low shear rate, which are all independent of $\alpha_{111} \beta_{3}$ activation but strictly dependent on $\mathrm{Ca}^{2+}$ mobilization. ${ }^{1649}$ Indeed, we found that $\mathrm{Ca}^{2+}$ mobilization induced by various agonists is defective in PT-VWD platelets. Platelet function was impaired in response to agonists stimulating both G-protein-coupled and ITAM-coupled receptors. In platelets, the generation of the $\mathrm{Ca}^{2+}$ and DAG second messengers leads to the activation of PKC. This activates Rap1 $b^{31,34}$ which, in turn, activates $\alpha_{11 b} \beta_{3}$ through the recruitment of Talin1. ${ }^{44}$ Therefore, we assessed Rap-1b activation and we found it impaired not due to a dysfunction of its main activator PLC $\beta_{3}$, but to a defective PKC pathway which contributes to its activation. ${ }^{34,45}$ This finding, together with our finding that ristocetin triggers PKC substrate phosphorylation in control platelets, suggests that enhanced VWF-GPIbo interaction leads to the activation and subsequent exhaustion of the PKC pathway, as recently described in 2B-VWD platelets. ${ }^{43}$ This, in turn, reduces Rap-1b activation, causing $\alpha_{11 b} \beta_{3}$ dysfunction. The binding of VWF to GPIb $\alpha$ activates PKC through a signaling cascade that involves Lyn, ${ }^{46}$ a SFK that we found to be activated in resting PT-VWD platelets. Thus, it can be hypothesized that the cause of baseline PKC upregulation, and the relative refractoriness of this pathway to stimulation, is Lyn activation. In addition, the activation of Lyn negatively regulates $\mathrm{Ca}^{2+}$ flux, and, consequently, platelet activation, through the activation of phosphatases. ${ }^{47}$ Taken together, our data show a global defect of platelet 
A

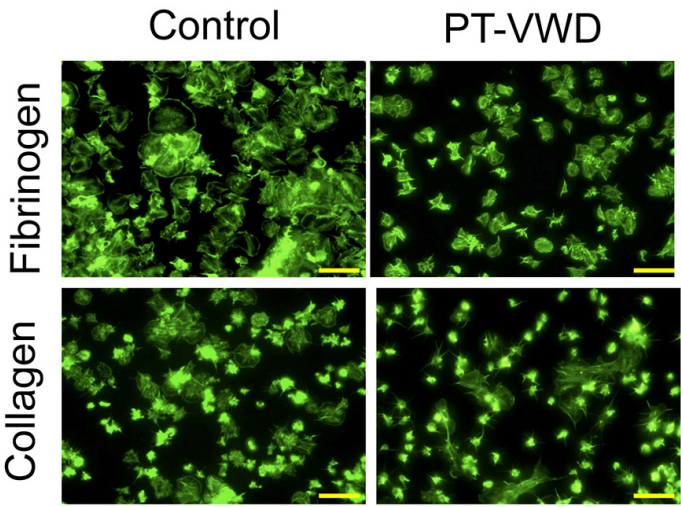

B

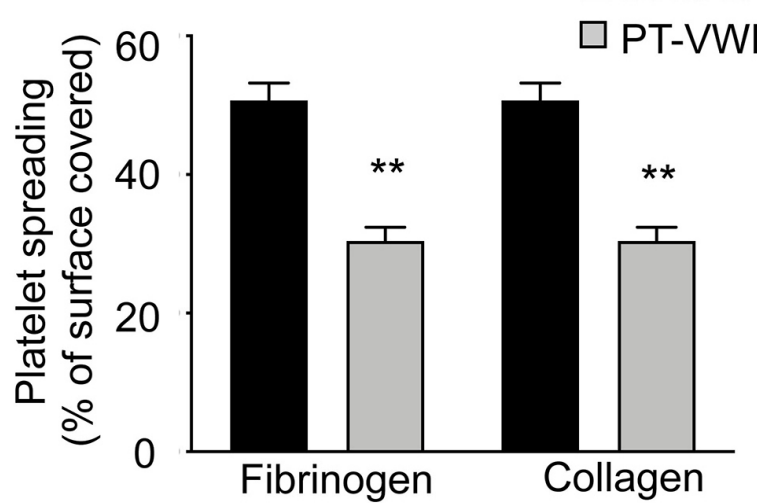

D

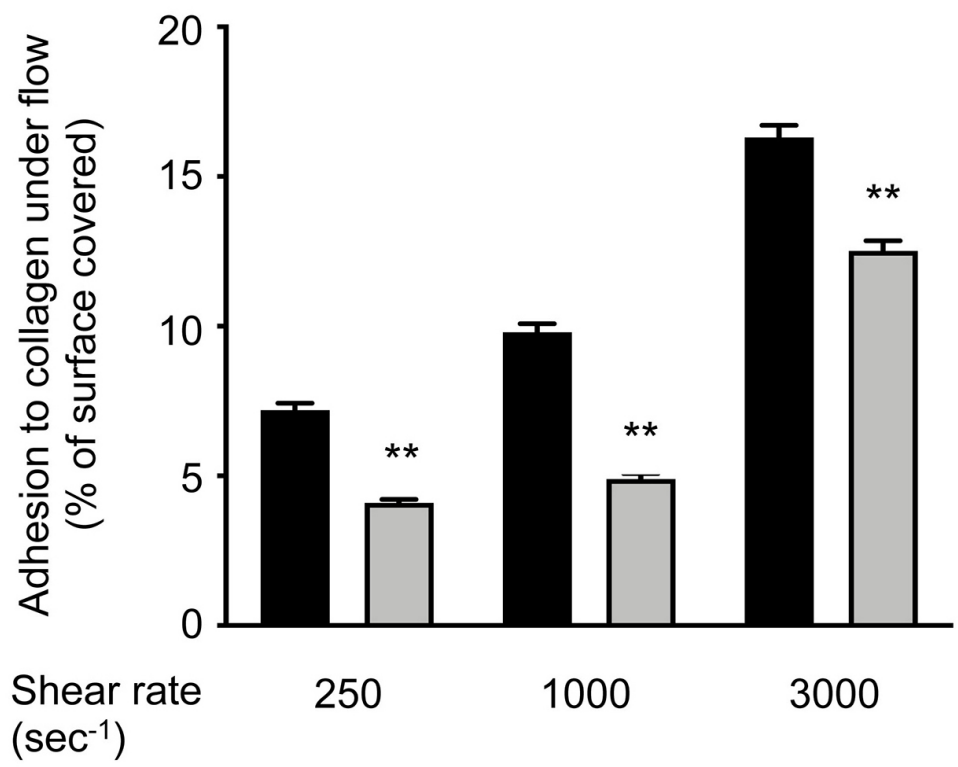

E

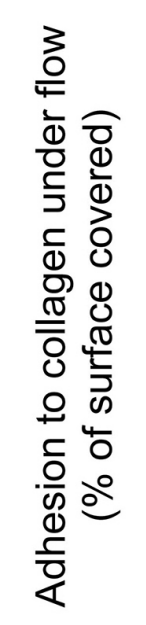

Shear rate
TgWT $\square \mathrm{Tg}^{\mathrm{G} 233 \mathrm{~V}}$

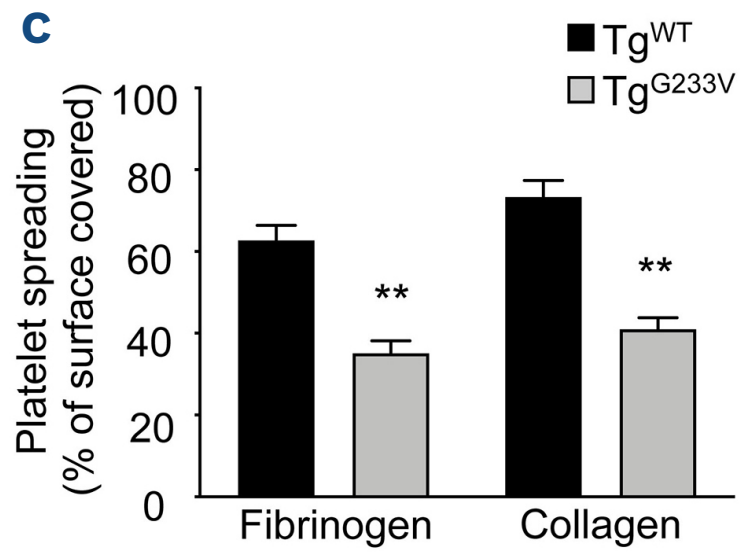

Figure 3. Platelet spreading and adhesion under flow conditions are defective in PT-VWD. (A) Representative images of human control and patient (PT-VWD) platelets 30 minutes after layering onto fibrinogen or collagen. Scale bar is $10 \mu \mathrm{m}$. Platelets were stained with FITC-conjugated phalloidin and analyzed using a Carl Zeiss Axio Observer.A1 fluorescence microscope (Carl Zeiss Inc., Oberkochen, Germany) with a 100x/1.4 Plan-Apochromat oil-immersion objective at room temperature. (B, C) Human (B) and murine (C) platelet spreading on glass coverslips coated with fibrinogen $(100 \mu \mathrm{g} / \mathrm{mL})$ or type I collagen $(25 \mu \mathrm{g} / \mathrm{mL})$. Spreading is expressed as percentage of surface covered by platelets. Data are means \pm SEM from five independent experiments (Online Supplementary Table S1, samples A, B, C, D, E) or from $\mathrm{n}=5$ mice ( $\mathrm{T}^{\mathrm{WWT}}$ : two females and three males, mean platelet count: $661600 \pm 99984 / \mu \mathrm{L} ; \mathrm{Tg}^{\mathrm{G} 233 \mathrm{~V}}$ : two females and three males; mean platelet count: $\left.305000 \pm 26728 / \mu \mathrm{L}\right)$. $\star \star * P<0.01 ;$ two-way ANOVA. The number of platelets that adhered to the surface was comparable between control and PT-VWD platelets (number of platelets adhering to fibrinogen per microscopic field: controls $93 \pm 27$, PT-VWD $87 \pm 18, P=$ ns; number of platelets adhering to collagen per microscopic field: controls 78 \pm 17 , PT-VWD $83 \pm 12, P=n s$ ) and between $\mathrm{Tg}^{\mathrm{WT}}$ and $\mathrm{Tg}^{\mathrm{G} 233 \mathrm{~V}}$ platelets (number of platelets adhering to fibrinogen per microscopic field: $\operatorname{Tg}^{\mathrm{WT}} 101 \pm 21, \mathrm{Tg}^{\mathrm{G} 233 \mathrm{~V}} 105 \pm 24, P=\mathrm{ns}$; number of platelets adhering to collagen per microscopic field: $\operatorname{Tg}^{\mathrm{WT}} 98 \pm 9$, $\mathrm{Tg}^{\mathrm{G} 233 \mathrm{~V}} 91 \pm 13, P=\mathrm{ns}$ ). (D-E) Human (D) and murine (E) platelet adhesion to type I collagen under flow conditions. Whole blood was perfused at different shear rates in glass microcapillary tubes coated with type I collagen (30 $\mu \mathrm{g} / \mathrm{cm}^{2}$ ). Specimens were observed under an optical microscope after fixation with $0.25 \%$ glutaric-dialdehyde and MayGrünwald/Giemsa staining. The total surface covered by platelets was calculated with ImageJ software. Data are means \pm SEM of three independent experiments (Online Supplementary Table S1, samples B, D, F) (D) or from $\mathrm{n}^{2} 3 \mathrm{mice}$ (Tg ${ }^{\mathrm{WT}}$ : three males, mean platelet count: $631550 \pm 21142 / \mu \mathrm{L}$; $\operatorname{Tg}^{\mathrm{G} 233 \mathrm{~V}}$ : three males; mean platelet count: $\left.350800 \pm 94469 / \mu \mathrm{L}\right)(\mathrm{E}) .{ }^{\star} P<0.05, \star \star P<0.01 ; \mathrm{two}-$ way ANOVA.

function in PT-VWD suggestive of the triggering of a negative feedback regulatory system. The binding of VWF to the extracellular region of GPIb $\alpha$ induces the association of Src and Lyn with the cytoplasmic tail of GPIba, starting the downstream phosphorylation of a number of substrates such as PI3K, Akt, p38, syk and PLC, involved in inside-out signaling leading to Rap-1b, Talin-1 and, thus, $\alpha_{11 \mathrm{~b}} \beta_{3}$ activation. ${ }^{6,35,48}$ However, in activated platelets, Lyn also initiates a negative feedback regulatory pathway by phosphorylating PECAM1, providing docking sites for SH2 domains of phosphatases such as the SHP1/SHP2 tyrosine phosphatases and the SHIP1/SHIP2 inositol phosphatase that mediate the termination of platelet activation signals. ${ }^{36,49-54}$
In our study, we show that Lyn and PECAM1 are activated in resting PT-VWD platelets identifying, to the best of our knowledge, the first platelet function defect due to the hyper-activation of Lyn and PECAM1 in humans. CAMP and cGMP production were comparable in control and PT-VWD platelets, indicating that these two negative platelet regulatory pathways are not involved in the platelet dysfunction of PT-VWD. Moreover, we show that Lyn and PECAM1 are activated in control platelets stimulated with ristocetin, confirming that the binding of VWF to GPIba phosphorylates Lyn and PECAM1. ${ }^{35,54}$

In support of our findings is the observation that platelets from PECAM1-knock-out, Lyn-knock-out, or PECAM1/Lyn 

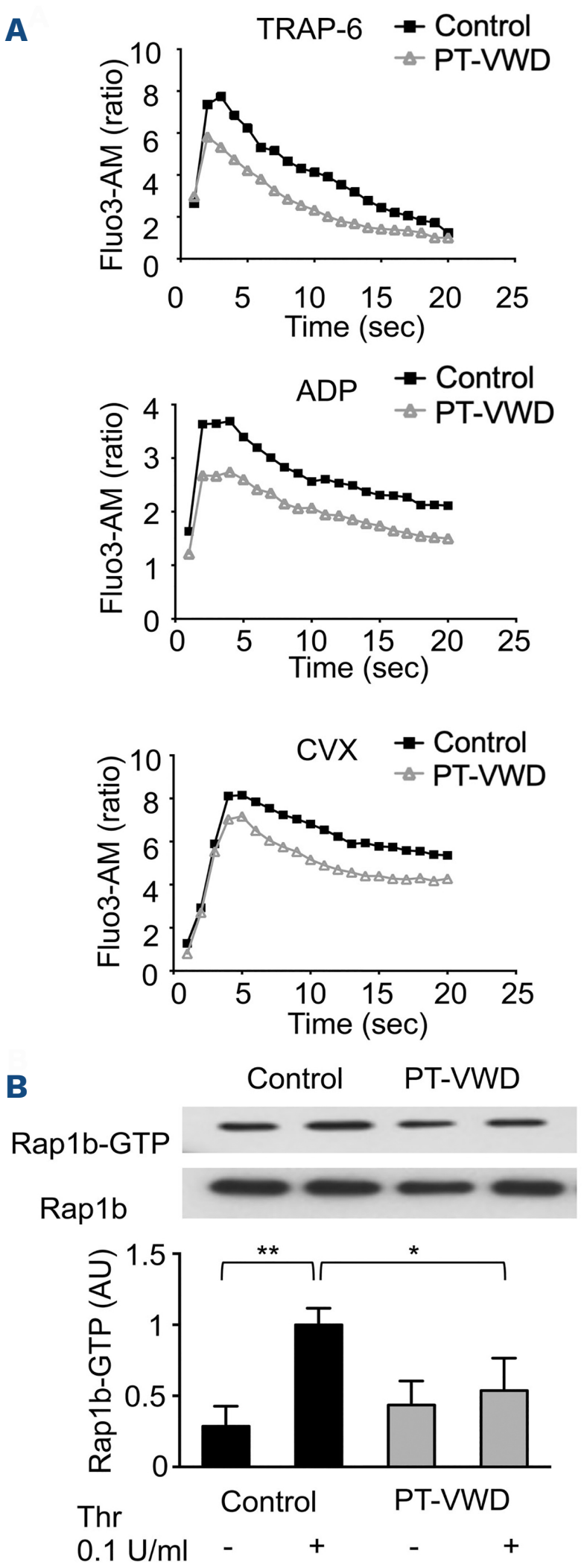
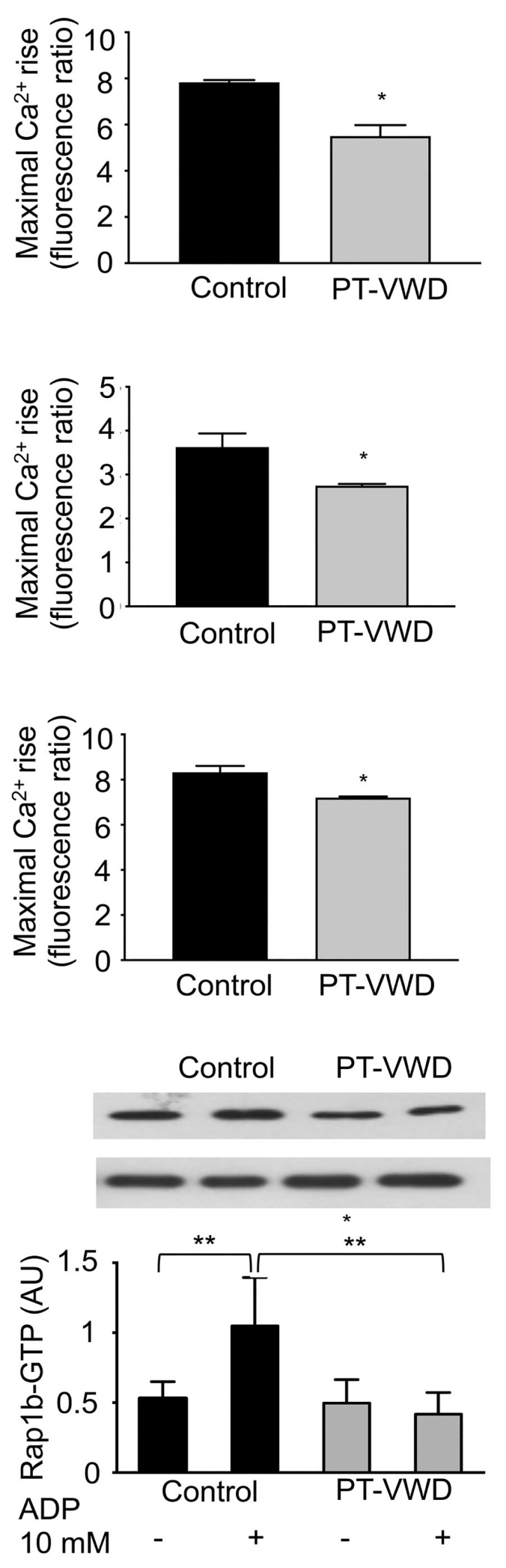

Figure 4. Platelet $\mathrm{Ca}^{2+}$ mobilization and Rap-1b activation are defective in PT-VWD. (A) Changes in cytosolic free $\mathrm{Ca}^{2+}$ triggered by TRAP- $610 \mu \mathrm{M}$, ADP 5 $\mu \mathrm{M}$ and $\mathrm{CVX} 50 \mathrm{ng} / \mathrm{mL}$, as assessed in FLUO 3-AM (8 $\mu \mathrm{M})$-labeled platelets. After the measurement of baseline fluorescence of PRP samples, agonists were added and changes in green fluorescence were recorded in function of time. The graphs show data from one representative experiment. Points represent the ratio with respect to baseline mean fluorescence intensity (MFI). The columns show maximal $\mathrm{Ca}^{2+}$ rise after stimulation (fluorescence ratio) with different agonists. Data are means \pm SEM from four independent experiments (Online Supplementary Table S1, samples D, E, F, H) $(P<0.05$; unpaired $t$-test). (B) Rap1b activation (Rap1b-GTP) of human control and patient (PT-VWD) platelets after stimulation with thrombin $(0.1 \mathrm{U} / \mathrm{mL})$ or ADP $(10 \mu \mathrm{M})$ under stirring conditions was assessed by western blotting by loading $500 \mu \mathrm{g}$ of proteins. Densitometric analysis was performed using Image $J$ software. Quantification of Rap1b-GTP is relative to total RAP1b expression and is expressed in arbitrary units $(A U)$. Data are means \pm SEM from three independent experiments (Online Supplementary Table S1, samples B, D, F) $\left({ }^{*} P<0.05\right.$; two-way ANOVA). double-knock-out mice are hyper-responsive to stimuli, confirming that PECAM1 and Lyn suppress platelet reactivity. ${ }^{36,51,53,54}$ To assess whether the blockade of Lyn could restore normal platelet reactivity, we measured granule secretion and $\alpha_{\| b} \beta_{3}$ activation by control and PT-VWD platelets after incubation with the Lyn inhibitor, bafetinib. However, bafetinib, suppressing the platelet activating function of Lyn, inhibited $\alpha_{11 \mathrm{~b}} \beta_{3}$ activation and granule secretion $^{35}$ (Online Supplementary Figure S9).

Conversely, human and murine platelets in which PECAM1 activation was triggered by a PECAM1 homophilic ligand ${ }^{50}$ or by cross-linking antibodies ${ }^{51,52}$ showed decreased aggregation, ${ }^{50,51}$ secretion, ${ }^{51,52} \mathrm{Ca}^{2+}$ mobilization ${ }^{51,52}$ and fibrinogen binding, ${ }^{52}$ all functions that we found to be impaired in PTVWD platelets. Indeed, PECAM1 has recently been identified as a potential novel target for antiplatelet therapy. ${ }^{55}$
Interestingly, PECAM1-knockout mice also show reduced trabecular bone volume, an increased number of osteoclasts and enhanced bone resorption ${ }^{56}$ while PT-VWD mice show enhanced trabecular bone volume, a decreased number of osteoclasts and decreased bone resorption, findings so far unexplained and possibly related to the role of PECAM1 as a negative regulator of osteoclastogenesis. ${ }^{12}$ When we assessed the activation of Lyn substrates, namely Akt and Syk, we found decreased Akt phosphorylation after stimulation with ADP and convulxin in PT-VWD platelets. The same Akt dysfunction was previously reported in $2 \mathrm{~B}-$ VWD platelets ${ }^{43}$ and is in line with the key role played by Akt in GPIb/IX/V-mediated $\alpha_{11 b} \beta_{3}$ integrin-dependent adhesion, spreading, and aggregation. ${ }^{57}$

In conclusion, our study shows that the constitutive binding of VWF to GPIba in PT-VWD platelets triggers deranged sig- 
naling, leading to the inhibition of $\alpha_{11 \mathrm{~b}} \beta_{3}$ activation, defective secretion and impaired platelet adhesion. Together, these generate a platelet function defect that may significantly contribute to the bleeding phenotype of these patients.
This mechanism may also account for the worsening of the bleeding diathesis of PT-VWD patients in conditions associated with an increase of circulating VWF, and therefore of its enhanced binding to GPIba, such as surgery or preg-
A

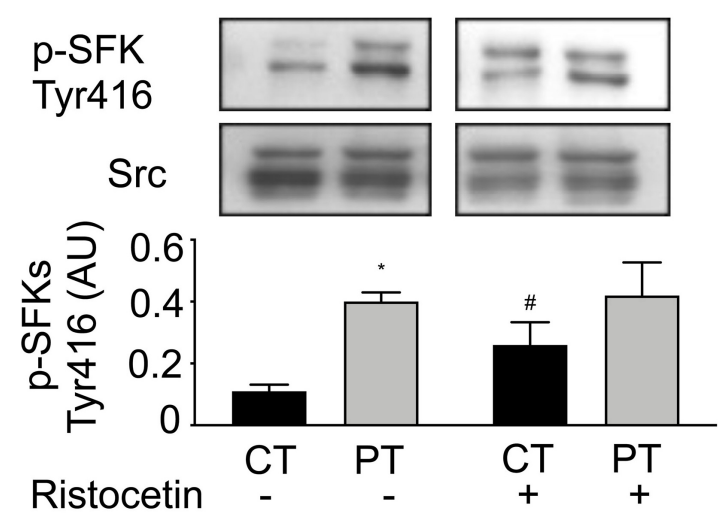

B
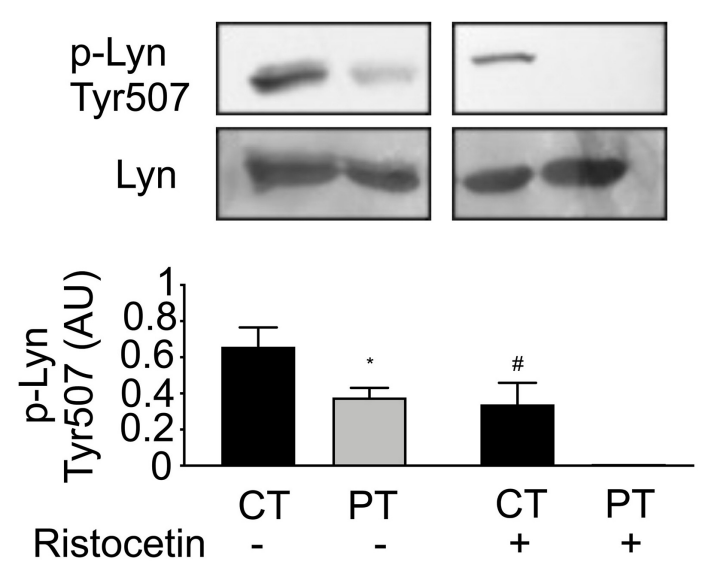

C

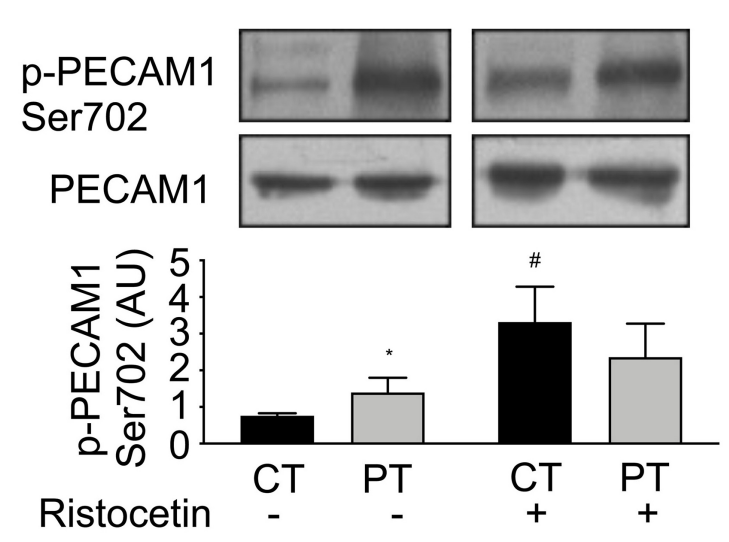

D

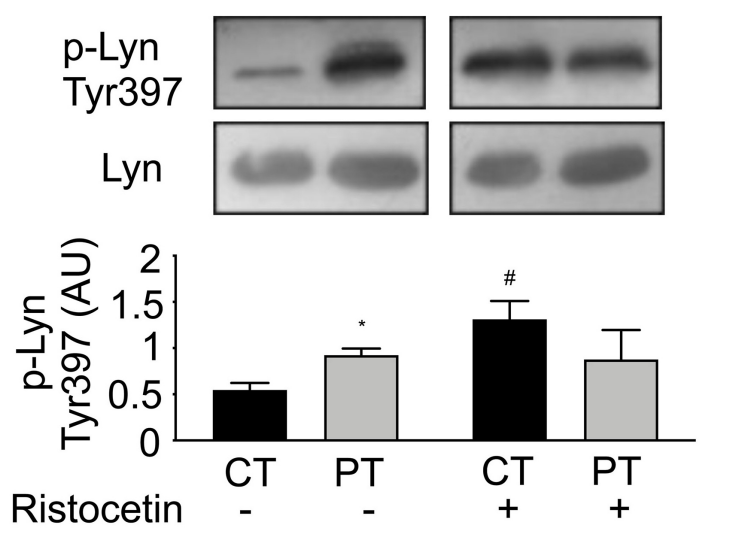

E

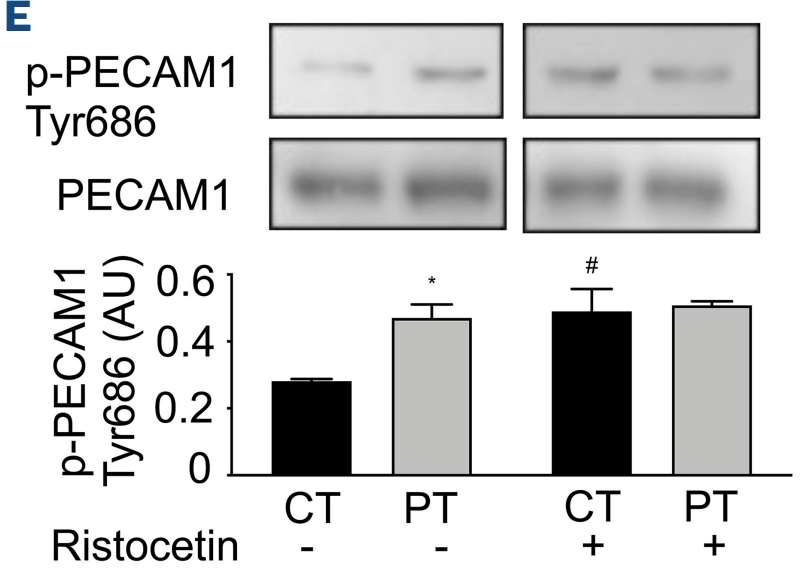

$\mathbf{F}$

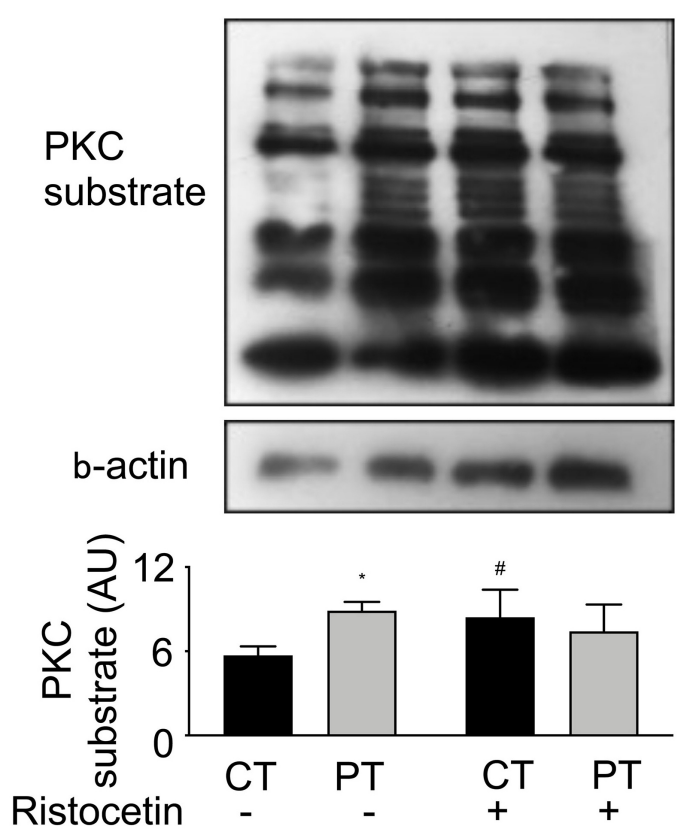

Figure 5. SFK, Lyn and PECAM-1 are constitutively phosphorylated in PT-VWD platelets. (A) SFK phosphorylation at Tyr 416 in human control and patient (PT-VWD) washed platelets unstimulated (-) or stimulated with ristocetin (0.3 $\mathrm{mg} / \mathrm{mL})$ for $30 \mathrm{sec}$ under stirring conditions, was assessed by western blotting by loading $30 \mu \mathrm{g}$ of proteins. Densitometric analysis of the pSFK/total SFK ratio was performed using Image $J$ software and is expressed in arbitrary units (AU). Data are means \pm SEM from six independent experiments (Online Supplementary Table S1, samples C, D, E, F, G, H) (*P<0.05 vs. control; ${ }^{*} P<0.05$ vs. resting; two-way ANOVA). The bands shown for resting platelets and platelets stimulated with ristocetin belong to the same gel. (B) Lyn phosphorylation at Tyr397 in human control and patient (PT-VWD) washed platelets unstimulated (-) or stimulated with ristocetin $(0.3 \mathrm{mg} / \mathrm{mL})$ for $30 \mathrm{sec}$ under stirring conditions, was assessed by western blotting by loading $30 \mu \mathrm{g}$ of proteins. Densitometric analysis of the pLyn/total Lyn ratio was performed using Image $\mathrm{J}$ software and is expressed in arbitrary units (AU). Data are means \pm SEM from six independent experiments (Online Supplementary Table S1, samples C, D, E, F, G, H) (*P<0.05 vs. control; ${ }^{P} P<0.05$ vs. resting; two-way ANOVA). The bands shown for resting platelets and platelets stimulated with ristocetin belong to the same gel. (C) Lyn phosphorylation at Tyr507 in human control and patient (PT-VWD) washed platelets unstimulated $(-)$ or stimulated with ristocetin $(0.3 \mathrm{mg} / \mathrm{mL})$ for $30 \mathrm{sec}$ under stirring conditions, was assessed by western blotting by loading $30 \mu \mathrm{g}$ of proteins. Densitometric analysis of the pLyn/total Lyn ratio was performed using Image $\mathrm{J}$ software and is expressed in 
arbitrary units (AU). Data are means \pm SEM from three independent experiments (Online Supplementary Table S1, samples F, G, H) ( $P<0.05$ vs. control; $P<0.05$ vs. resting; two-way ANOVA). The bands shown for resting platelets and platelets stimulated with ristocetin belong to the same gel. (D) PECAM1 phosphorylation at Tyr686 in human control and patient (PT-VWD) washed platelets unstimulated (-) or stimulated with ristocetin $(0.3 \mathrm{mg} / \mathrm{mL})$ for $30 \mathrm{sec}$ under stirring conditions, was assessed by western blotting by loading $30 \mu \mathrm{g}$ of proteins. Densitometric analysis of the pPECAM1/total PECAM1 ratio was performed using Image $\mathrm{J}$ software and is expressed in arbitrary units (AU). Data are means \pm SEM from six independent experiments (Online Supplementary Table S1, samples C, D, E, F, G, H) ( ${ }^{*} P<0.05$ vs. control; ${ }^{*} P<0.05$ vs. resting; two-way ANOVA). The bands shown for resting platelets and platelets stimulated with ristocetin belong to the same gel. (E) PECAM1 phosphorylation at Ser702 in human control and patient (PT-VWD) washed platelets unstimulated (-) or stimulated with ristocetin (0.3 $\mathrm{mg} / \mathrm{ml})$ for $30 \mathrm{sec}$ under stirring conditions, was assessed by western blotting by loading $30 \mu \mathrm{g}$ of proteins. Densitometric analysis of the PPECAM1/total PECAM1 ratio was performed using Image $\mathrm{J}$ software and is expressed in arbitrary units (AU). Data are means \pm SEM from three independent experiments (Online Supplementary Table S1, samples F, G, H) (*P<0.05 vs control; ${ }^{*} P<0.05$ vs. resting; two-way ANOVA). The bands shown for resting platelets and platelets stimulated with ristocetin belong to the same gel. (F) PKC substrate phosphorylation in human control and patient (PT-VWD) washed platelets unstimulated (-) or stimulated with ristocetin $(0.3 \mathrm{mg} / \mathrm{mL})$ for $30 \mathrm{sec}$ under stirring conditions, was assessed by loading $30 \mu \mathrm{g}$ of proteins. Densitometric analysis of the PKC substrate/actin ratio was performed using Image $\mathrm{J}$ software and is expressed in arbitrary units (AU). Data are means \pm SEM from four independent experiments (Online Supplementary Table S1, samples E, F, G, H) ( ${ }^{*} P<0.05$ vs. control; ${ }^{*} P<0.05$ vs. resting; two-way ANOVA). The bands shown for resting platelets and platelets stimulated with ristocetin belong to the same gel.

nancy. ${ }^{35-37}$ Our data obtained with platelets carrying two different GP1BA gain-of-function variants suggest that the platelet function defect in PT-VWD is independent of the GP1BA variant type and is due to the enhanced affinity of GPIba for VWF. However, it should be noted that the variants we studied affect the same domain of GPIb $\alpha$, therefore we cannot predict the effects on platelet function of variants in other domains. ${ }^{58} \mathrm{~A}$ similar mechanism for platelet dysfunction may play a role in the platelet dysfunction of 2B-VWD. Indeed, results of studies with human and murine 2B-VWD platelets carrying the p.V1316M VWF variant are similar to results of the present study. Both disorders share the same platelet function defect, characterized by $\alpha_{\| 1} \beta_{3}$ dysfunction, $\alpha$ - and $\delta$-granule secretion defect, defective $\mathrm{Ca}^{2+}$ signaling and adhesion under flow conditions. ${ }^{5,42}$ Defective Rap1b and Akt activation and PKC upregulation with consequent desensitization have been shown for both disorders, ${ }^{43}$ together with a dysregulation of the RhoA pathway. ${ }^{59}$ It would be interesting to assess Lyn and PECAM1 phosphorylation in 2B-VWD platelets to check whether the same negative-feedback loop downregulating platelet activation here described is present in 2B-VWD.

Finally, our results imply that inhibitors of PECAM1 might be explored to restore platelet function in PT-VWD. However, the PECAM1 blockers currently available are antibodies that block PECAM1 adhesive interactions ${ }^{60-63}$ and not PECAM1 phosphorylation or downstream signaling, therefore they do not allow assessment of whether PECAM1 blockade might restore normal platelet function.

The development of PECAM1 inhibitors selectively suppressing intracellular phosphorylation might represent a novel approach to the antihemorrhagic treatment of PTVWD.

\section{Disclosures}

No conflicts of interest to disclose.

\section{Contributions}

$L B, E F, A M M, G G$ and SM performed experiments, analyzed and interpreted data; $P G$ designed and supervised the study; PG contributed the patient for the study; $L B$ and $P G$ wrote the manuscript; $P G$ critically revised the manuscript.

\section{Acknowledgments}

The continued collaboration of our PT-VWD patient is gratefully acknowledged.

\section{Funding}

This work was supported by a Telethon grant (GGP15063) to $P G$ and by a fellowship by Fondazione Umberto Veronesi to $L B$ and EF. The authors thank Prof. Jerry Ware (University of Arkansas, USA) and Dr. Maha Othman (Queen's University, Canada) for kindly providing the $\operatorname{Tg}^{W T}$ and $\operatorname{Tg}^{\mathrm{G} 233 \mathrm{~V}}$ mice and Prof. Debra K. Newman (Medical College of Wisconsin, USA) for the kind gift of the anti PECAM1 antibody.

\section{Data-sharing statement}

All data generated or analyzed during this study are included in this article and its supplementary material files. Further enquiries can be directed to the corresponding author.

\section{References}

1. Othman M, Kaur H, Emsley J. Platelet-type von Willebrand disease: new insights into the molecular pathophysiology of a unique platelet defect. Semin Thromb Hemost.

2013;39(6):663-673.
2. Othman M, Kaur H, Favaloro EJ, et al. Platelet type von Willebrand disease and registry report: communication from the SSC of the ISTH. J Thromb Haemost. 2016;14(2):411-414.

3. Gresele P, Bury L, Falcinelli E. Inherited platelet function 
disorders: algorithms for phenotypic and genetic investigation. Semin Thromb Hemost. 2016;42(3):292-305.

4. Guerrero JA, Kyei M, Russell S, et al. Visualizing the von Willebrand factor/glycoprotein Ib-IX axis with a platelet-type von Willebrand disease mutation. Blood. 2009;114(27):5541-5546.

5. Kaur H, Corscadden K, Ware J, Othman M. Thrombocytopathy leading to impaired in vivo haemostasis and thrombosis in platelet type von Willebrand disease. Thromb Haemost. 2017;117(3):543-555.

6. Kasirer-Friede A, Cozzi MR, Mazzucato M, De Marco L, Ruggeri ZM, Shattil SJ. Signaling through GP Ib-IX-V activates alpha IIb beta 3 independently of other receptors. Blood. 2004;103(9):3403-3411.

7. Li Z, Zhang G, Feil R, Han J, Du X. Sequential activation of p38 and ERK pathways by CGMP-dependent protein kinase leading to activation of the platelet integrin alphallb beta3. Blood. 2006;107(3):965-972.

8. Yin H, Liu J, Li Z, Berndt MC, Lowell CA, Du X. Src family tyrosine kinase Lyn mediates VWF/GPIb-IX-induced platelet activation via the cGMP signaling pathway. Blood. 2008;112(4):1139-1146.

9. Giannini S, Cecchetti L, Mezzasoma AM, Gresele P. Diagnosis of platelet-type von Willebrand disease by flow cytometry. Haematologica. 2010;95(6):1021-1024.

10. Bury L, Malara A, Momi S, Petito E, Balduini A, Gresele P. Mechanisms of thrombocytopenia in platelet-type von Willebrand disease. Haematologica. 2019;104(7):1473-1481.

11. Gresele P, Orsini S, Noris P, et al. Validation of the ISTH/SSC bleeding assessment tool for inherited platelet disorders: a communication from the Platelet Physiology SSC. J Thromb Haemost. 2020;18(3):732-739.

12. Suva LJ, Hartman E, Dilley JD, et al. Platelet dysfunction and a high bone mass phenotype in a murine model of platelet-type von Willebrand disease. Am J Pathol. 2008;172(2):430-439.

13. Gresele P, Falcinelli E, Giannini S, et al. Dominant inheritance of a novel integrin beta3 mutation associated with a hereditary macrothrombocytopenia and platelet dysfunction in two Italian families. Haematologica. 2009;94(5):663-669.

14. Vezza R, Spina D, Tallarida RJ, Nathan M, Page CP, Gresele P. Antivasoconstrictor and antiaggregatory activities of picotamide unrelated to thromboxane A2 antagonism. Thromb Haemost. 1997;78(5):1385-1391.

15. Riondino S, Lotti LV, Cutini L, Pulcinelli FM. Collagen-induced platelet shape change is not affected by positive feedback pathway inhibitors and CAMP-elevating agents. J Biol Chem. 2005;280(8):6504-6510.

16. DiMinno G, Silver MJ. Mouse antithrombotic assay: a simple method for the evaluation of antithrombotic agents in vivo. Potentiation of antithrombotic activity by ethyl alcohol. $J$ Pharmacol Exp Ther. 1983;225(1):57-60.

17. Sebastiano M, Momi S, Falcinelli E, Bury L, Hoylaerts MF, Gresele P. A novel mechanism regulating human platelet activation by MMP-2-mediated PAR1 biased signaling. Blood. 2017;129(7):883-895.

18. Mumford AD, Frelinger AL 3rd, Gachet C, et al. A review of platelet secretion assays for the diagnosis of inherited platelet secretion disorders. Thromb Haemost. 2015;114(1):14-25.

19. Canobbio I, Cipolla L, Consonni A, et al. Impaired thrombininduced platelet activation and thrombus formation in mice lacking the $\mathrm{Ca}(2+)$-dependent tyrosine kinase Pyk2. Blood. 2013;121(4):648-657.

20. Cozzi MR, Guglielmini G, Battiston M, et al. Visualization of nitric oxide production by individual platelets during adhesion in flowing blood. Blood. 2015;125(4):697-705.
21. Wall JE, Buijs-Wilts M, Arnold JT, et al. A flow cytometric assay using mepacrine for study of uptake and release of platelet dense granule contents. $\mathrm{Br} J$ Haematol. 1995;89(2):380-385.

22. Mustard JF, Perry DW, Ardlie NG, Packham MA. Preparation of suspensions of washed platelets from humans. $\mathrm{Br} J$ Haematol. 1972;22(2):193-204.

23. Momi S, Falcinelli E, Giannini S, et al. Loss of matrix metalloproteinase 2 in platelets reduces arterial thrombosis in vivo. J Exp Med. 2009;206(11):2365-2379.

24. Bury L, Falcinelli E, Chiasserini D, Springer TA, Italiano JE Jr., Gresele P. Cytoskeletal perturbation leads to platelet dysfunction and thrombocytopenia in variant forms of Glanzmann thrombasthenia. Haematologica. 2016;101(1):46-56.

25. Momi S, Impagnatiello F, Guzzetta M, et al. NCX 6560, a nitric oxide-releasing derivative of atorvastatin, inhibits cholesterol biosynthesis and shows anti-inflammatory and anti-thrombotic properties. Eur J Pharmacol. 2007;570(1-3):115-124.

26. do Ceu Monteiro M, Sansonetty F, Goncalves MJ, O'Connor JE. Flow cytometric kinetic assay of calcium mobilization in whole blood platelets using Fluo-3 and CD41. Cytometry. 1999;35(4):302-310.

27. Amison RT, Momi S, Morris A, et al. RhoA signaling through platelet $\mathrm{P} 2 \mathrm{Y}(1)$ receptor controls leukocyte recruitment in allergic mice. J Allergy Clin Immunol. 2015;135(2):528-538.

28. Paddock C, Lytle BL, Peterson FC, et al. Residues within a lipidassociated segment of the PECAM-1 cytoplasmic domain are susceptible to inducible, sequential phosphorylation. Blood. 2011;117(22):6012-6023.

29. Guglielmini G, Appolloni V, Momi S, et al. Matrix metalloproteinase-2 enhances platelet deposition on collagen under flow conditions. Thromb Haemost. 2016;115(2):333-343.

30. Lopez E, Bermejo N, Berna-Erro A, et al. Relationship between calcium mobilization and platelet alpha- and delta-granule secretion. A role for TRPC6 in thrombin-evoked delta-granule exocytosis. Arch Biochem Biophys. 2015;585:75-81.

31. Franke B, Akkerman JW, Bos JL. Rapid Ca2+-mediated activation of Rap1 in human platelets. EMBO J. 1997;16(2):252-259.

32. Li Z, Delaney MK, O'Brien KA, Du X. Signaling during platelet adhesion and activation. Arterioscler Thromb Vasc Biol. 2010;30(12):2341-2349.

33. Anguita E, Villalobo A. Src-family tyrosine kinases and the $\mathrm{Ca}(2+)$ signal. Biochim Biophys Acta Mol Cell Res. 2017;1864(6):915-932.

34. Cifuni SM, Wagner DD, Bergmeier W. CalDAG-GEFI and protein kinase $C$ represent alternative pathways leading to activation of integrin alphallbbeta3 in platelets. Blood. 2008;112(5):1696-1703.

35. Senis YA, Mazharian A, Mori J. Src family kinases: at the forefront of platelet activation. Blood. 2014;124(13):2013-2024.

36. Ming Z, Hu Y, Xiang J, Polewski P, Newman PJ, Newman DK. Lyn and PECAM-1 function as interdependent inhibitors of platelet aggregation. Blood. 2011;117(14):3903-3906.

37. Noris P, Schlegel N, Klersy C, et al. Analysis of 339 pregnancies in 181 women with 13 different forms of inherited thrombocytopenia. Haematologica. 2014;99(8):1387-1394.

38. O'Connor D, Lester W, Willoughby S, Wilde JT. Pregnancy in platelet-type VWD: a case series. Thromb Haemost. 2011;106(2):386-387.

39. Orsini S, Noris P, Bury L, et al. Bleeding risk of surgery and its prevention in patients with inherited platelet disorders. Haematologica. 2017;102(7):1192-1203.

40. Sanchez-Luceros A, Woods AI, Bermejo E, et al. PT-VWD posing diagnostic and therapeutic challenges - small case series. Platelets. 2017;28(5):484-490. 
41. Kaur H, Ozelo M, Scovil S, James PD, Othman M. Systematic analysis of bleeding phenotype in PT-VWD compared to type 2B VWD using an electronic bleeding questionnaire. Clin Appl Thromb Hemost. 2014;20(8):765-771.

42. Casari C, Berrou E, Lebret M, et al. von Willebrand factor mutation promotes thrombocytopathy by inhibiting integrin alphallbbeta3. J Clin Invest. 2013;123(12):5071-5081.

43. Casari C, Paul DS, Susen $S$, et al. Protein kinase $C$ signaling dysfunction in von Willebrand disease (p.V1316M) type 2B platelets. Blood Adv. 2018;2(12):1417-1428.

44. Guidetti GF, Torti M. The small GTPase Rap1b: a bidirectional regulator of platelet adhesion receptors. J Signal Transduct. 2012;2012:412089.

45. Harper MT, Poole AW. Diverse functions of protein kinase $C$ isoforms in platelet activation and thrombus formation. $J$ Thromb Haemost. 2010;8(3):454-462.

46. Liu J, Pestina TI, Berndt MC, Jackson CW, Gartner TK. Botrocetin/VWF-induced signaling through GPIb-IX-V produces TxA2 in an alphallbbeta3- and aggregation-independent manner. Blood. 2005;106(8):2750-2756.

47. Maxwell MJ, Yuan Y, Anderson KE, Hibbs ML, Salem HH, Jackson SP. SHIP1 and lyn kinase negatively regulate integrin $\alpha$ llb $\beta 3$ signaling in platelets. J Biol Chem. 2004;279(31):32196-32204.

48. Wu Y, Asazuma N, Satoh K, et al. Interaction between von Willebrand factor and glycoprotein Ib activates Src kinase in human platelets: role of phosphoinositide 3-kinase. Blood. 2003;101(9):3469-3476.

49. Newman PJ, Newman DK. Signal transduction pathways mediated by PECAM-1: new roles for an old molecule in platelet and vascular cell biology. Arterioscler Thromb Vasc Biol. 2003;23(6):953-964.

50. Jones KL, Hughan SC, Dopheide SM, Farndale RW, Jackson SP, Jackson DE. Platelet endothelial cell adhesion molecule- 1 is a negative regulator of platelet-collagen interactions. Blood. 2001;98(5):1456-1463.

51. Cicmil M, Thomas JM, Leduc M, Bon C, Gibbins JM. Platelet endothelial cell adhesion molecule-1 signaling inhibits the activation of human platelets. Blood. 2002;99(1):137-144.

52. Jones Cl, Garner SF, Moraes LA, et al. PECAM-1 expression and activity negatively regulate multiple platelet signaling pathways.
FEBS Lett. 2009;583(22):3618-3624.

53. Crockett J, Newman DK, Newman PJ. PECAM-1 functions as a negative regulator of laminin-induced platelet activation. $J$ Thromb Haemost. 2010;8(7):1584-1593.

54. Rathore V, Stapleton MA, Hillery CA, et al. PECAM-1 negatively regulates GPIb/V/IX signaling in murine platelets. Blood. 2003;102(10):3658-3664.

55. Soriano Jerez EM, Gibbins JM, Hughes CE. Targeting platelet inhibition receptors for novel therapies: PECAM-1 and G6b-B. Platelets. 2021;32(6):761-769.

56. Wu Y, Tworkoski K, Michaud M, Madri JA. Bone marrow monocyte PECAM-1 deficiency elicits increased osteoclastogenesis resulting in trabecular bone loss. J Immunol. 2009;182(5):2672-2679.

57. Yin H, Stojanovic A, Hay N, Du X. The role of Akt in the signaling pathway of the glycoprotein Ib-IX induced platelet activation. Blood. 2008;111(2):658-665.

58. Othman M, Notley C, Lavender FL, et al. Identification and functional characterization of a novel 27-bp deletion in the macroglycopeptide-coding region of the GPIBA gene resulting in platelet-type von Willebrand disease. Blood. 2005;105(11):4330-4336.

59. Kauskot A, Poirault-Chassac S, Adam F, et al. LIM kinase/cofilin dysregulation promotes macrothrombocytopenia in severe von Willebrand disease-type 2B. JCI Insight. 2016;1(16):e88643.

60. Qing Z, Sandor M, Radvany Z, et al. Inhibition of antigen-specific $T$ cell trafficking into the central nervous system via blocking PECAM1/CD31 molecule. J Neuropathol Exp Neurol. 2001;60(8):798-807.

61. Bogen S, Pak J, Garifallou M, Deng X, Muller WA. Monoclonal antibody to murine PECAM-1 (CD31) blocks acute inflammation in vivo. J Exp Med. 1994;179(3):1059-1064.

62. Dasgupta B, Chew T, deRoche A, Muller WA. Blocking platelet/endothelial cell adhesion molecule 1 (PECAM) inhibits disease progression and prevents joint erosion in established collagen antibody-induced arthritis. Exp Mol Pathol. 2010;88(1):210-215.

63. Woodfin A, Voisin MB, Nourshargh S. PECAM-1: a multi-functional molecule in inflammation and vascular biology. Arterioscler Thromb Vasc Biol. 2007;27(12):2514-2523. 